\title{
Very Low Density Lipoproteins in Intestinal Lymph: Origin, Composition, and Role in Lipid Transport in the Fasting State
}

\author{
Robert K. Ockner, Fatth B. Hughes, and Kurt J. Isselbacher \\ From the Department of Medicine, Harvard Medical School and the Medical \\ Services, Massachusetts General Hospital, Boston, Massachusetts 02114
}

A BSTRACT The transport of endogenous lipids in the lipoproteins of mesenteric lymph was studied in fasting rats with mesenteric lymph fistulas. The lymph was found to contain, in addition to chylomicrons $\left(\mathrm{S}_{2}>\right.$ 400 ), a significant amount of another, more dense, triglyceride-rich fraction, the very low density lipoproteins (VLDL), which showed a peak $S_{t}$ of 102. The VLDL differed from chylomicrons not only in flotation, but also in per cent lipid composition and electrophoretic mobility in agarose gel. The VLDL fraction was found to contain $47 \%$ of the triglyceride and $54 \%$ of the cholesterol of fasting lymph and, in the fasting state, was the major lipoprotein species present.

When cholestyramine resin was administered intraduodenally, or bile flow was acutely diverted from the intestine, it was demonstrated that the lipids in lymph VLDL, like those in chylomicrons, were derived from the intestine and bile. These data indicate that the VLDL in intestinal lymph are not derived from the plasma but are of intestinal origin.

Because certain properties of lymph VLDL were similar to those reported for plasma VLDL (per cent lipid composition, flotation coefficient, and continuing entry into plasma in the fasting state), additional comparisons between these fractions were made. Although lymph VLDL moved to the $\alpha_{2}$ region in agarose gel, when they were mixed with VLDL-free serum immediately before electrophoresis they showed the $\alpha_{1}$ mobility of rat serum VLDL. Furthermore, immunoelectrophoretic comparison of partially delipidated lymph and serum VLDL revealed that these fractions shared in

These studies were presented in part at the annual meeting of the American Society of Clinical Investigation, Atlantic City, N. J., 1968.

Dr. Ockner's present address is Department of Medicine, University of California, San Francisco Medical Center, San Francisco, Calif. 94122.

Received for publication 28 April 1969. common their major apoprotein, and possibly others as well. The fatty acid composition of lymph and serum triglycerides, as determined by gas-liquid chromatography, revealed that although they were generally similar, differences existed which most likely reflected the presence in serum of triglycerides of hepatic origin.

These experiments demonstrate the importance of intestinal VLDL in the transport of endogenous lipids in mesenteric lymph in the fasting state. The similarities between intestinal lymph VLDL and plasma VLDL suggest that the latter may be derived in part from the former.

\section{INTRODUCTION}

It is known that dietary lipids are absorbed by the small intestine and transported in the lymphatics to the systemic circulation as chylomicrons. These particles, defined by Zilversmit as alimentary triglyceride-rich lipoproteins of $S_{e}$ greater than 400 (1), have been shown to be rapidly removed from the plasma by liver and peripheral adipose tissue $(2-4)$. As they are not present to any significant extent in the normal fasting or postabsorptive state, the intestine has been generally regarded as an organ whose role in lipoprotein metabolism is limited to its absorption of dietary lipid.

Recent evidence, however, has suggested that the intestine may play a broader role in lipid and lipoprotein metabolism. For example, it has been shown that the small intestine synthesizes cholesterol $(5,6)$, and may contribute significantly to circulating plasma cholesterol levels $(7,8)$. Furthermore, hepatectomized animals are capable of incorporating radioactive fatty acids into plasma triglycerides (9) and radioactive amino acids into plasma very low density lipoproteins (VLDL), probably as the result of intestinal lipoprotein synthesis (10). 
In recent studies we have observed that with both fasting and feeding, the intestinal lymph contains triglyceride-rich particles similar to plasma very low density lipoproteins and differing from chylomicrons in flotation, composition, and electrophoretic mobility (11, 12). Although these very low density lipoproteins and the chylomicrons may be opposite ends of a single spectrum of particle size and density, their dissimilarities suggested the possibility that they play different roles in lipid metabolism.

The present studies were undertaken in order to characterize intestinal lymph VLDL and determine their source. Other experiments dealing with their role in the transport of specific lipids will be reported subsequently. ${ }^{1}$

\section{METHODS}

Animals. All these experiments were carried out using $300-400 \mathrm{~g}$ male albino CD strain rats, ${ }^{2}$ maintained before study on a standard laboratory diet. ${ }^{3}$ Cannulation of the mesenteric lymphatic duct was carried out under light pentobarbital anesthesia by a modification of the procedure described by Bollman, Cain, and Grindlay (13). In addition, a polyethylene catheter for infusion of test solutions was inserted into the duodenum near the entrance of the common bile duct. After operation, animals were placed in restraining cages (14) and received $0.85 \% \mathrm{NaCl}$ or $5 \%$ glucose in $0.85 \%$ $\mathrm{NaCl}$, either ad lib. or by intraduodenal infusion. Animals were allowed to stabilize at least overnight after surgery. On some occasions animals were used on the second morning after operation, but no difference in lymph composition was noted between these two periods.

Collection and handling of samples. In most experiments involving a $3 \mathrm{hr}$ test period, animals received intraduodenal infusions of $0.85 \% \mathrm{NaCl}$. Lymph was collected at room temperature, the volume recorded, and samples were defibrinated at the end of the collection. For longer collections, the tubes were kept in ice. After defibrination portions of these samples were either refrigerated for subsequent chemical analysis or were subjected without delay to preparative ultracentrifugation.

Preparative ultracentrifugation. Samples of lymph were placed in cellulose nitrate tubes, and were centrifuged at $3 \times 10^{\circ} \mathrm{g} \cdot \mathrm{min}, 10^{\circ} \mathrm{C}$, in a Beckman Spinco SW 39 swinging bucket rotor. Under these conditions lipoprotein particles having $S_{\&}$ greater than 400 rose to the surface (15) and were designated "chylomicrons" (1). This fraction was separated from the immediately underlying lymph subnatant by means of a tube slicer. The lymph subnatant was then centrifuged at $10^{8} \mathrm{~g} \cdot \mathrm{min}$ in order to float all remaining particles of density (d) less than 1.006, designated "very low density lipoproteins" (VLDL). This fraction was separated from the remaining portion of lymph, designated $d>1.006$.

Quantities of lipids in the various fractions were calculated as follows: chylomicron: whole lymph minus lymph subnatant; VLDL: lymph subnatant minus $\mathrm{d}>1.006$; and

${ }^{1}$ Ockner, R. K., F. B. Hughes, and K J. Isselbacher. Very low density lipoproteins in intestinal lymph: role in triglyceride and cholesterol transport during fat absorption. In press.

${ }^{2}$ Charles River Laboratories, Wilmington, Mass.

- Purina Lab Chow, Ralston-Purina Co., St. Louis, Mo. $\mathrm{d}>1.006$ : determined directly. In a control experiment, purified chylomicrons and VILDL of known lipid composition were mixed, allowed to stand, and subsequently separated by preparative ultracentrifugation under conditions duplicating those of the experiments. It was found that there was no significant net movement of cholesterol between the two fractions. There did appear to be some movement of triglyceride from the chylomicron fraction to the lymph subnatant but, because in other experiments marked variations in chylomicron triglyceride were not associated with changes in VLDL triglyceride, ${ }^{1}$ it was concluded that this movement was not of practical significance under the actual conditions of the experiments.

In those cases in which individual lipoprotein fractions were analyzed for lipid and protein composition, the fractions were subjected to at least two additional ultracentrifugations under the conditions described above, except that the isolated fractions were each time layered under $0.85 \% \mathrm{NaCl}$. By this technique contaminating plasma proteins in lymph were removed from the samples being analyzed (12).

Analytical ultracentrifugation. Samples of intestinal lymph were subjected to preparative ultracentrifugation (3 $\times 10^{6} \mathrm{~g} \cdot \mathrm{min}$ ) as described above in order to remove the chylomicrons. The lymph subnatant was adjusted to a density of $1.063 \mathrm{~g} / \mathrm{ml}$ (16) and the VLDL and low density lipoproteins (LDL) were collected by means of a second preparative ultracentrifugation $\left(10^{8} \mathrm{~g} \cdot \mathrm{min}\right)$. These lipoproteins were resuspended in 1.745 molal $\mathrm{NaCl}$ (density $1.063 \mathrm{~g} / \mathrm{ml}$ ), and were placed in a Spinco double-sectored cell with a $12 \mathrm{~mm}$ filled Epon centerpiece and sapphire windows. The sample was run in a Spinco Model $\mathrm{E}$ analytical ultracentrifuge at $26^{\circ} \mathrm{C}$ and $33,450 \mathrm{rpm}$, with an up-to-speed time of $2.23 \mathrm{~min}$. Photographs of the Schlieren pattern were taken at 2-min intervals, and $S_{f}$ value calculated from the formula $\mathrm{S}_{\mathrm{f}}=\frac{1}{\omega^{2}} \frac{(\mathrm{d} \ln x)}{(\mathrm{dt})}$ where $\omega$ is angular velocity in radians/ sec, $x$ is distance from the axis of rotation in centimeters and $t$ is time in seconds (17).

Chomical assays. Lymph and lymph fractions were analyzed for content of triglyceride (18) and total free and ester cholesterol (19) as previously described (20). Phospholipid content was determined by a modification of the method of Bartlett (21). Total protein in lipoprotein fractions was measured by the method of Lowry, Rosebrough, Farr, and Randall (22) after partial ethanol ether delipidation (23) or with ether extraction of lipid after color development (comparable results).

Gas-liquid chromatography. In some experiments total lipids were extracted from the samples by the method of Folch, Lees, and Sloane-Stanley (24), and the triglycerides isolated by thin-layer chromatography. Triglyceride fatty acid methyl esters were prepared by a modification of the procedure of Lipsky and Landowne (25) and were analyzed by means of a Barber-Colman gas chromatograph, model 5000 (hydrogen flame detector) on a $6 \mathrm{ft}$ column packed with $15 \%$ ethylene glycol succinate on Chromosorb W, $60-80$ mesh, at $170^{\circ} \mathrm{C}$ with nitrogen flow at 14 PSI. Per cent composition of the fatty acid methyl ester mixture was determined by planimetry.

Electrophoretic and immunochemical techniques. Samples of lymph, serum, or lipoprotein fractions were subjected to electrophoresis on paper by the method of Lees and Hatch (26), or in agarose gel by the method of Laurell (27). Native and delipidated lipoprotein fractions were subjected to immunoelectrophoresis in agar gel $(12,28)$. Rabbit antiserum to rat intestinal lymph VLDL (12) was placed in all 


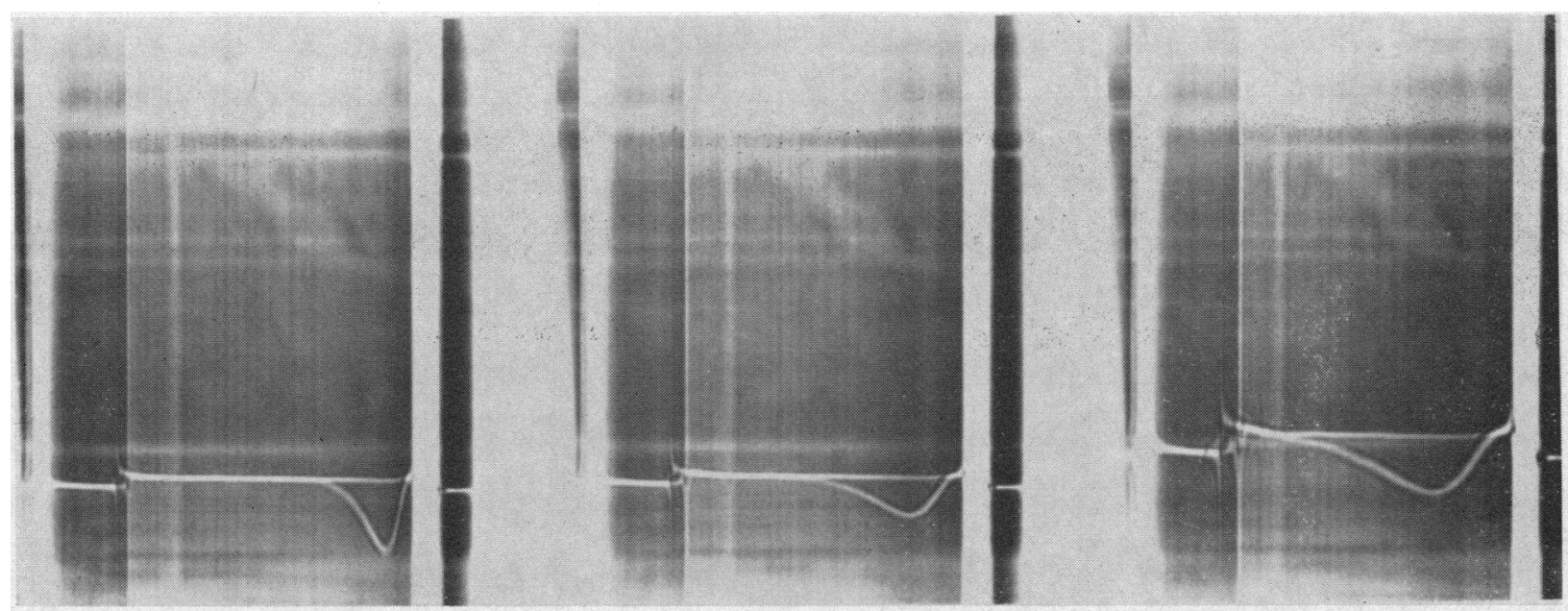

FJgURE 1 Flotation analysis of rat intestinal lymph subnatant lipoproteins. Medium density $1.063 \mathrm{~g} / \mathrm{ml} ; 26^{\circ} \mathrm{C} ; 33,450 \mathrm{rpm}$; up-to-speed time $134 \mathrm{sec}$. Schlieren patterns (from left to right) are 0,120 , and $240 \mathrm{sec}$ after attained speed and reveal particles of broad flotation range, with peak at $S_{\mathbf{t}} 102$.

troughs, and precipitin patterns were allowed to develop over a $48-72 \mathrm{hr}$ period.

Statistical methods. Differences in lipid and protein composition between chylomicrons and VLDL were tested for statistical significance by Student's $t$ test (29).

\section{RESULTS}

Analytical ultracentrifugation of lymph subnatant. Since the conditions used for the separation of chylomicrons from other lipoprotein fractions of intestinal lymph in the preparative ultracentrifuge were based on theoretical predictions from the nomogram of Dole and Hamlin (15), it was necessary to confirm directly the flotation rates of lymph subnatant (chylomicron free) lipoproteins by analytical ultracentrifugation (Fig. 1). It is seen that these lipoprotein classes include particles of a broad density range, with a peak at $S_{2} 102$. Thus, the particles designated "VLDL" in the present experiments are within the appropriate flotation range ( $\mathrm{S}_{\mathrm{r}} 20$ 400 ), and do not merely represent chylomicrons ( $S_{r}>$ 400 ) incompletely removed by preparative ultracentrifugation.

Electrophoretic properties of lymph VLDL and chylomicrons. Preparations of lymph VLDL and chylomicrons were subjected to electrophoresis on filter paper and in agarose gel. Although both fractions remained at the origin on paper, they differed significantly in their mobilities in agarose (Fig. 2). In this medium, chylomicrons remained at the origin, whereas VLDL moved in the region of the $\alpha_{2}$ globulins. The "tailing" exhibited by both fractions is consistent with the broad range of particle size characteristic of these lipoprotein classes.

Composition of intestinal lymph VLDL and chylomicrons. Preparations of lymph VLDL and chylomi- crons, purified by means of additional "washes" in the preparative ultracentrifuge, were analyzed for their lipid and protein composition (Table I). These fractions exhibited highly significant differences in their content of triglyceride, phospholipid, and cholesterol. Although there was a suggestion of a higher protein content in VLDL, the number of samples was not adequate to show statistical significance. It is of additional interest that whereas only about one-half of the chylo-

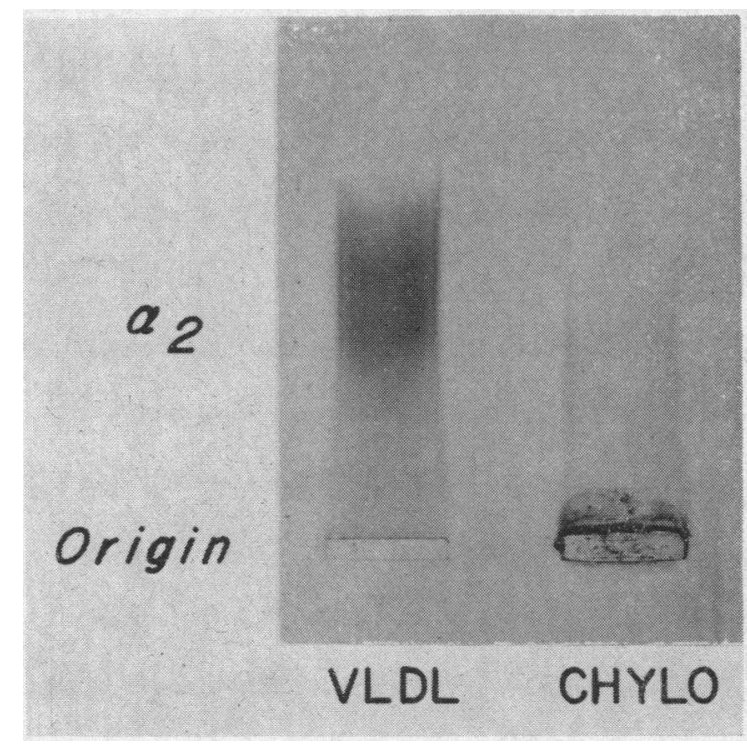

FIgure 2 Agarose-gel electrophoresis of intestinal lymph VLDL and chylomicrons. Purified lipoprotein fractions were suspended in isotonic $\mathrm{NaCl}$ and subjected to agarose-gel electrophoresis as described in Methods. Pictured is the fixed and dried gel after staining with oil red 0 . 
TABLE I

Composition of Intestinal Lymph Chylomicrons and Very Low Density Lipoproteins (VLDL)

\begin{tabular}{|c|c|c|c|c|c|}
\hline $\begin{array}{l}\text { Lipoprotein } \\
\text { fraction }\end{array}$ & Triglyceride & Phospholipid & $\begin{array}{c}\text { Free } \\
\text { cholesterol }\end{array}$ & $\begin{array}{c}\text { Ester } \\
\text { cholesterol }\end{array}$ & Protein \\
\hline & \multicolumn{5}{|c|}{$\% *$} \\
\hline Chylomicrons & $81.7 \pm 3.5$ & $13.8 \pm 2.7$ & $1.1 \pm 0.3$ & $1.0 \pm 0.1$ & $2.3 \pm 1.0$ \\
\hline VLDL & $66.8 \pm 1.0$ & $24.3 \pm 1.6$ & $2.2 \pm 0.2$ & $4.2 \pm 0.2$ & $3.3 \pm 1.2$ \\
\hline Significance & $P<0.001$ & $P<0.001$ & $P<0.01$ & $P<0.001$ & $0.2<P<0.3$ \\
\hline
\end{tabular}

Aliquots of saline suspensions of purified lipoprotein fractions were analyzed for concentration of individual lipids and of protein as described in Methods. Per cent values reflect the ratio of the concentration of each component to that of the sum of the five components in each sample.

* Mean \pm 1 SD (four experiments).

micron cholesterol was esterified, in the VLDL twothirds was in ester form.

Triglycerides were isolated by thin-layer chromatography from fasting lymph VLDL and chylomicrons, and the methyl esters of the triglyceride fatty acids were analyzed by gas-liquid chromatography (GLC) (Table II). No significant differences in the fasting triglyceride fatty acid composition of the lipoprotein fractions were apparent, although in other studies it was shown that considerable differences develop during lipid absorption. ${ }^{1}$

Lipoprotein distribution of endogenous lymph triglyceride and cholesterol. Over a $3 \mathrm{hr}$ collection period, fasting lymph fistula rats received an intraduodenal infusion of $15 \mathrm{ml}$ of $0.85 \% \mathrm{NaCl}$ ( $5 \mathrm{ml}$ from 0 to $30 \mathrm{~min}$; $10 \mathrm{ml}$ from 60 to $180 \mathrm{~min}$ ). It is seen (Table III) that significant quantities of triglyceride and cholesterol appeared in intestinal lymph. These quantities did not decrease significantly even after several days without dietary fat.

Analysis of the lipoprotein distribution of these lipids showed VLDL to be the major lipid-carrying fraction of fasting intestinal lymph, accounting for approximately $50 \%$ of the total triglyceride and cholesterol (Table III). Although the chylomicrons carried nearly

TABLE II

Triglyceride Fatty Acid Composition of Fasting Intestinal Lymph Chylomicrons and VLDL

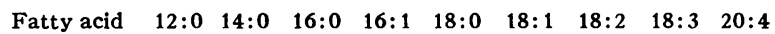

\begin{tabular}{llllllllll} 
& \multicolumn{1}{c}{$\%$} & $\%$ \\
VIDL & tr.* & tr. & 25.2 & tr. & 12.7 & 15.6 & 28.3 & 6.6 & 11.5
\end{tabular}

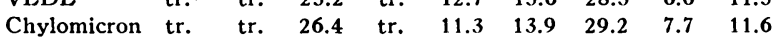

Per cent composition represents ratio of area under GLC curve for each fatty acid to sum of areas for all fatty acids, as determined by planimetry. Each value is the mean of two (VLDI) or three (chylomicrons) determinations, each from different animals.

$*$ tr. $=$ trace, i.e. $<1 \%$. the same amount of triglyceride as did the VLDL, less than $20 \%$ of the cholesterol appeared in this fraction.

Source of intestinal lymph VLDL. Because VLDL circulate in plasma, it was necessary to consider the possibility that intestinal lymph VLDL were merely plasma VLDL which appeared in lymph along with other plasma proteins as a result of movement across the mesenteric capillary bed. To investigate this possibility, a saline suspension of cholestyramine resin was infused $(80 \mathrm{mg} / \mathrm{hr}$ ) into the duodenum of a lymph fistula rat, and the lipoprotein distribution of lymph triglyceride and cholesterol was determined. It was felt that cholestyramine, by binding intraluminal bile salts, would interfere with the micellar solubilization and absorption of intraluminal fatty acids and cholesterol, but would not affect lipoproteins entering the lymph from the

TABLE III

Distribution of Triglyceride and Cholesterol among Intestinal Lymph Lipoprotein Fractions in Fasting Rats

\begin{tabular}{lrrrr}
\hline & \multicolumn{2}{c}{ Triglyceride } & \multicolumn{2}{c}{ Cholesterol } \\
\hline \multirow{3}{*}{ Whole lymph } & \multicolumn{1}{c}{$\mathrm{mg}^{\prime} \mathrm{hr}$} & $\%^{*}$ & $m g / h r$ & $\% \%^{*}$ \\
& 5.90 & 100 & 0.519 & 100 \\
& \pm 1.47 & & \pm 0.128 & \\
Chylomicrons & 2.52 & 40.2 & 0.089 & 16.8 \\
& \pm 1.50 & \pm 15.6 & \pm 0.064 & \pm 12.3 \\
VLDL & 2.66 & 46.7 & 0.281 & 53.9 \\
& \pm 0.87 & \pm 18.2 & \pm 0.088 & \pm 7.2 \\
$\mathrm{~d}>1.006$ & 0.72 & 13.1 & 0.148 & 29.3 \\
& \pm 0.38 & \pm 9.2 & \pm 0.031 & \pm 6.7 \\
& & & &
\end{tabular}

Animals received intraduodenal isotonic $\mathrm{NaCl}, 5 \mathrm{ml} / \mathrm{hr}$. Lymph flow during the $3 \mathrm{hr}$ collection period was $2.2 \pm 0.6$ $\mathrm{ml} / \mathrm{hr}$. Values presented are the means of 6 experiments, $\pm 1 \mathrm{sD}$.

* Mean percentages are calculated from percentage distributions of individual animals rather than from the mean absolute distributions presented. 
plasma. In Fig. 3 it is seen that during the infusion of cholestyramine and for a period of time thereafter, the total lymph triglyceride and cholesterol fell rapidly to very low levels. This was almost entirely due to changes in chylomicron and VLDL lipids, with significantly less effect on lipoproteins of $d>1.006$.

Additional studies were carried out with lymph fistula rats in which a catheter connecting the bile duct to the duodenum was placed at the time of the formation of the lymph fistula. The catheter was sufficiently long to permit a portion of it to be exteriorized. By this technique, bile could be diverted acutely during an ex-

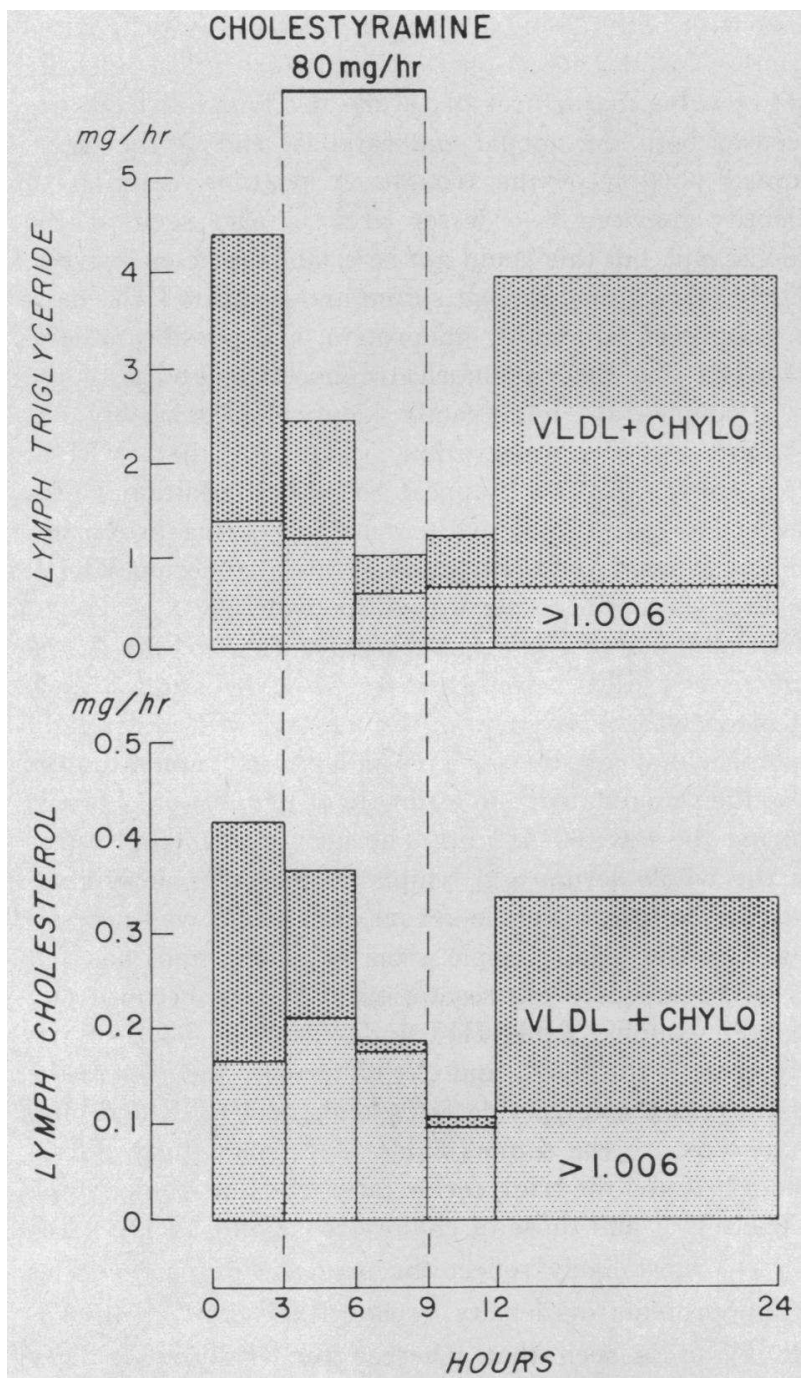

Figure 3 Effect of intraduodenal cholestyramine on lymph triglyceride and cholesterol. A fasting rat with intestinal lymph fistula received intraduodenal isotonic saline, or saline suspension of cholestyramine. Samples of whole lymph and d > 1.006 fraction were analyzed for lipid content (see Methods). Mean lymph flows before, during, and after cholestyramine : $2.9,1.7$, and $1.6 \mathrm{ml} / \mathrm{hr}$ respectively.

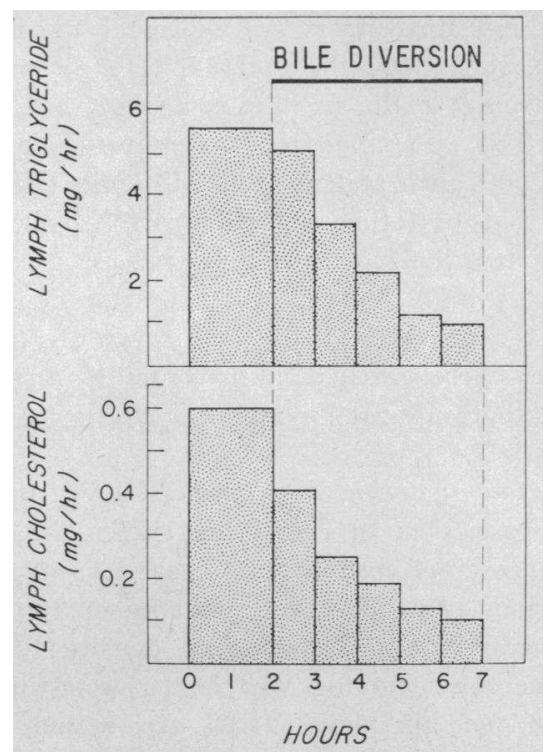

FIGURE 4 Effect of bile diversion on lymph triglyceride and cholesterol. A rat was prepared on the previous day with a mesenteric lymph fistula, intraduodenal catheter, and an exteriorized catheter connecting common bile duct to duodenum. After a control period $(0-2 \mathrm{hr})$, the bile duct catheter was divided resulting in acute bile diversion without operative stress. Samples of whole lymph were analyzed for lipid content, as in Methods. Lymph flow was at least 2.0 $\mathrm{ml} / \mathrm{hr}$ throughout experiment.

periment without subjecting the animal to additional operative stress. In Fig. 4, it is seen that bile diversion, like cholestyramine administration, resulted in a rapid fall in lymph triglyceride and cholesterol, to about $20 \%$ of their baseline levels.

These results indicate that about $80 \%$ of the total intestinal lymph triglyceride and cholesterol, and essentially all of that in VLDL and chylomicrons, is derived from the intestinal lumen and mucosa. It is concluded, therefore, that the VLDL in fasting intestinal lymph are not derived directly from the peripheral circulation. In other experiments, it was shown that whereas the rate of delivery of bile phospholipid to the intestine was sufficient to account for the fatty acids in VLDL and chylomicron triglycerides, the bile cholesterol could account for only about one-half to two-thirds of that portion of lymph cholesterol derived from the intestine." This is consistent with the remainder having been derived from the intestinal wall itself.

Relationship of intestinal lymph VLDL to plasma $V L D L$. The above evidence strongly suggested that intestinal lymph VLDL are of intestinal rather than plasma origin. However, the converse, i.e. that plasma VLDL might be derived in part from intestinal lymph VLDL, seemed worthy of consideration for several rea-

Unpublished observations. 
sons: (a) intestinal lymph VLDL enter the plasma in the fasting state; $(b)$ the flotation rate corresponds to that of plasma VLDL; $(c)$ the composition of intestinal lymph VLDL is similar to that reported for plasma VLDL of both man and rat $(30,31)$; and $(d)$ there is evidence that intestinal lymph VLDL, like plasma VLDL, contain both the $\mathrm{A}$ and $\mathrm{B}$ proteins (the apoproteins of $\alpha$ or high density, and $\beta$ or low density lipoproteins, respectively) (12,32). Accordingly, additional experiments were carried out in order to examine the possibility that intestinal lymph VLDL is a source of plasma VLDL.

Comparison of serum and lymph VLDL in agarose gel electrophoresis. In Fig. 5 are shown the oil red 0 s'ained agarose-gel electrophoretic patterns of $(a)$ fasting rat serum; $(b)$ the same serum subjected to preparative ultracentrifugation at its own density $\left(1.006,10^{8}\right.$ $\mathrm{g} \cdot \mathrm{min})$, thereby removing VLDL; $(c)$ intestinal lymph VLDL; and $(d)$ the above VLDL-free serum, to which intestinal lymph VLDL were added immediately before electrophoresis. The most intensely lipid-staining zone in serum has an $\alpha_{1}$ mobility, and is markedly diminished by ultracentrifugation, indicating that this zone corresponds to and contains VLDL. A saline suspension of intestinal lymph VLDL contains some particles which move to this region, but the great majority move more slowly, to the $\alpha_{2}$ region. However, when lymph VLDL are added to serum from which its own VLDL have been removed, a pattern identical with that of native serum is produced. This indicates that the electrophoretic mo-

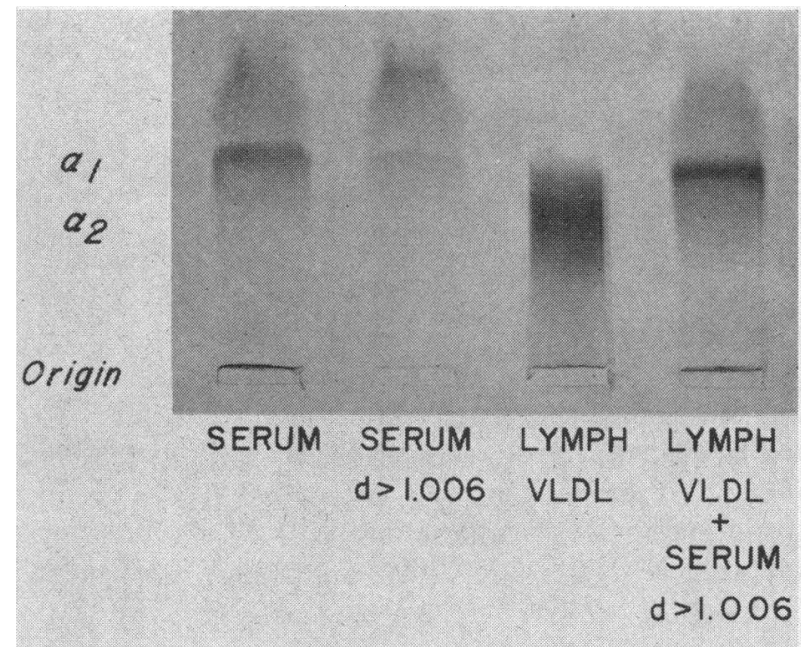

Figure 5 Agarose-gel electrophoresis of intestinal lymph and serum lipoproteins. The $d>1.006$ fraction of serum and purified intestinal lymph VLDL were prepared by ultracentrifugation. Lymph VLDL were suspended in isotonic $\mathrm{NaCl}$, and a sample was added to a sample of the serum d $>1.006$ fraction immediately before agarose-gel electrophoresis (Methods). Pictured is the fixed and dried gel after staining with oil red 0 . bility of lymph VLDL is altered by the presence of serum and becomes identical with that of the VLDL normally present in serum. The most likely explanation for this phenomenon is the adsorption of additional serum proteins or lipoproteins to the surface of the VLDL.

Immunoelectrophoretic comparison of delipidated intestinal lymph VLDL and serum VLDL. Purified preparations of partially delipidated fasting lymph and serum VLDL were compared by immunoelectrophoresis in agar gel using the interrupted trough technique (Fig. 6). All troughs contained rabbit antiserum to intestinal lymph VLDL. It is seen that the antiserum reveals the presence of one major and one or more minor precipitin arcs with both delipidated serum VLDL and delipidated lymph VLDL. Reactions of immunochemical identity between the major arcs of serum and lymph VLDL are seen at both the anodal and cathodal end of the interrupted portion of the trough. A possible reaction of identity between two lesser arcs is also seen at the anodal end, but this could not be established conclusively. These results suggest that serum and lymph VLDL have in common their major apoprotein, and possibly others. The fact that the immunoelectrophoretic patterns of the two samples are not exactly identical is probably explained by the observation (Fig. 5) that VLDL, upon entering plasma, appear to adsorb additional proteins. The large dense white areas appearing in the immunoelectrophoretic pattern of delipidated serum VLDL in Fig. 6 are due to denatured lipoprotein.

Comparison of triglyceride fatty acids in fasting lymph and serum. Rats were fasted for $36-48 \mathrm{hr}$, and a sample of blood was removed from the femoral vein under light pentobarbital anesthesia. The mesenteric lymphatic duct was then cannulated, and a sample of lymph was obtained during the next 30-45 min. The fatty acid methyl esters of the whole serum and lymph triglycerides were compared. The use of whole serum and lymph was necessitated by the small sample sizes available, and was felt to be an adequate representation of VLDL because $(a)$ in both lymph (Table III) and serum ${ }^{5} 80-90 \%$ of triglyceride is in VLDL and chylomicrons; and $(b)$ in the fasting state, triglyceride fatty acids of VLDL and chylomicrons are the same (Table II). (The slight differences between the triglyceride fatty acids of whole lymph (Table IV) and those of chylomicrons and VLDL (Table II) most likely reflect the presence of triglycerides in lipoproteins of density greater than 1.006). In Table IV it is seen that whereas the triglyceride fatty acids of lymph and serum are generally similar, they differ in their relative content of stearic $(18: 0)$ and arachidonic $(20: 4)$ acids, and to a lesser extent in their content of oleic $(18: 1)$ acid. These differences are con-

\footnotetext{
${ }^{5}$ Unpublished observations.
}

2084 R. K. Ockner, F. B. Hughes, and K. J. Isselbacher 


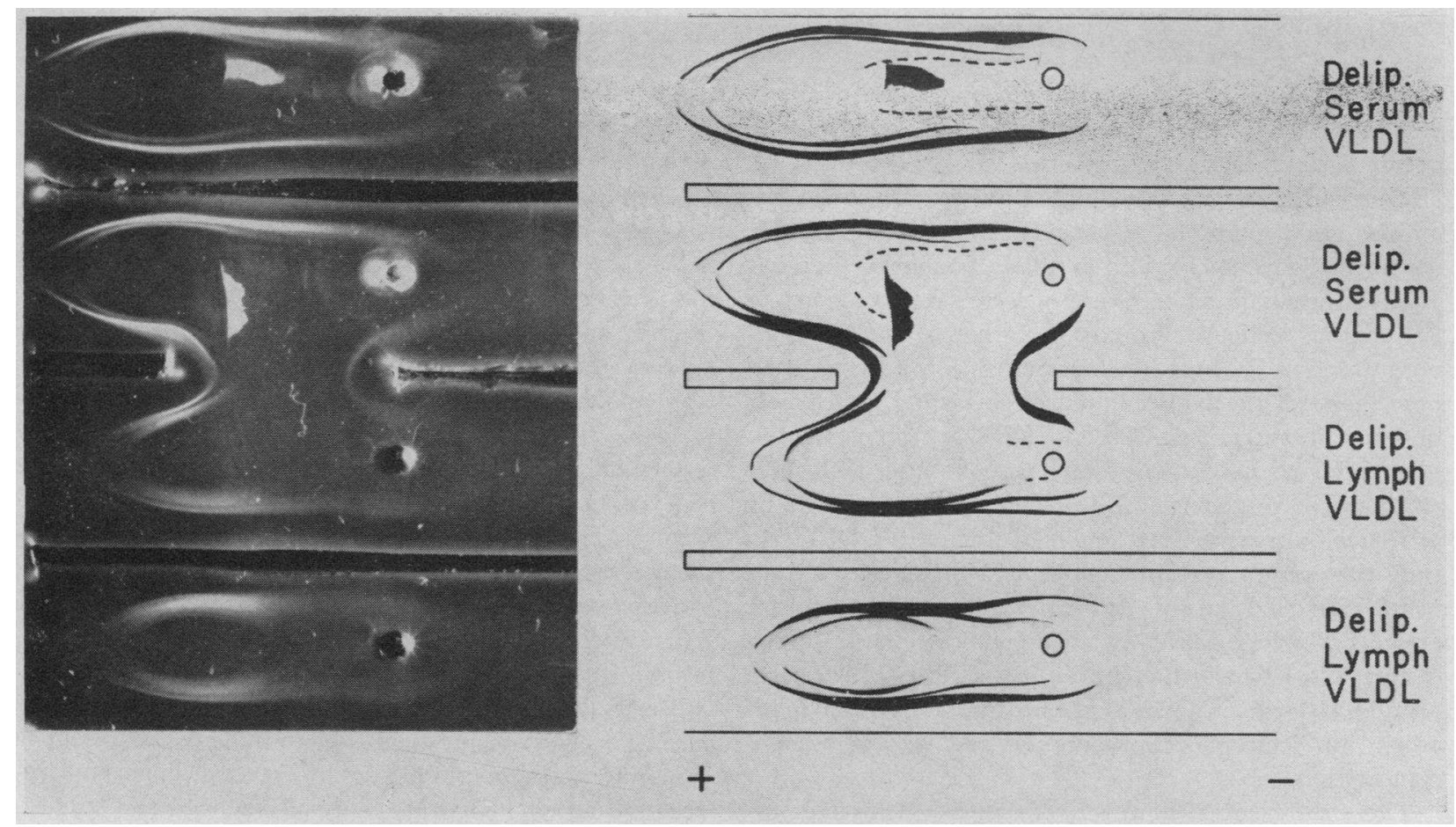

FIGLRE 6 Immunoelectrophoresis of partially delipidated VLDL from intestinal lymph and serum. The partially delipidated lipoproteins are compared in agar gel by the interrupted trough technique. All troughs contained antiserum to lymph VLDL. Purified lymph and serum VLDL were prepared by repeated ultracentrifugation, suspended in isotonic $\mathrm{NaCl}$, and partially delipidated (see Methods).

sistent with the presence of additional triglyceride in serum representing lipoproteins derived from the liver.

\section{DISCUSSION}

In the present studies, a nonchylomicron, triglycericlerich, very low density lipoprotein (VLDL) fraction of rat intestinal lymph has been isolated, characterized, and studied as to its role in the transport of endogenous lipicls. In the fasting state, VLDL were found to be quantitatively the must important lipoprotein fraction in intestinal lymph, containing $47 \%$ of the triglyceride and $54 \%$ of the cholesterol. In contrast, the chylomicrons under these conditions carry only $40 \%$ of the triglyceride and $17 \%$ of the cholesterol. Studies with intraduodenal infusion of cholestyramine or bile diversion indicate that the lipids in these two lipoprotein fractions are derived from bile and the intestinal wall.

VLDL and chylomicrons are both triglyceride-rich lipoproteins having a density less than plasma and isotonic saline $(1.005-1.006 \mathrm{~g} / \mathrm{ml}) \quad(30)$. Accordingly,

TABLE IV

Fatty Acid Composition of Triglycerides in Intestinal Lymph and Serum of Fasting Rats

\begin{tabular}{cccccccccc}
\hline $\begin{array}{c}\text { Source of } \\
\text { triglyceride }\end{array}$ & $12: 0$ & $14: 0$ & $16: 0$ & $16: 1$ & $18: 0$ & $18: 1$ & $18: 2$ & $18: 3$ & $20: 4$ \\
\hline \multirow{2}{*}{ Lymph } & tr. ${ }^{*}$ & tr. & $\begin{array}{c}30.3 \\
(28.9-31.6)\end{array}$ & tr. & $\begin{array}{c}10.9 \\
(9.8-12.0)\end{array}$ & $\begin{array}{c}17.5 \\
(14.8-19.6)\end{array}$ & $\begin{array}{c}25.4 \\
(25.0-25.8)\end{array}$ & tr. & $\begin{array}{c}15.0 \\
(13.9-15.8)\end{array}$ \\
Serum & tr. & tr. & $\begin{array}{c}29.4 \\
(29.2-29.9)\end{array}$ & tr. & $\begin{array}{c}4.7 \\
(3.8-5.4)\end{array}$ & $\begin{array}{c}27.5 \\
(26.0-29.2)\end{array}$ & $\begin{array}{c}31.9 \\
(30.4-34.1)\end{array}$ & tr. & $\begin{array}{c}6.0 \\
(5.4-7.3)\end{array}$ \\
\hline
\end{tabular}

Samples of intestinal lymph and serum were obtained from each of three animals as described in Methods. Fatty acid composition of whole serum and lymph TG determined as in Table II. Values shown are means and ranges for three samples.

*tr. $=$ trace, i.e. $<1 \%$. 
their separation and distinction by preparative ultracentrifugation must be based largely upon operational definitions. Zilversmit (1) defined "chylomicrons" as those triglyceride-rich alimentary particles with $S_{\&} 400$ or greater, and in almost all reported studies dealing with chylomicrons, particles in this $S_{t}$ range have been examined. In the present experiments, the conditions for separating chylomicrons from whole lymph by preparative ultracentrifugation were selected to conform to Zilversmit's criteria. As has been noted, the chylomicron fraction so prepared accounted for only a small percentage of the lymph lipid in the fasting state, most of which was found in VLDL. VLDL are defined as triglyceride-rich lipoproteins with an $S_{t}$ range of 20-400, and have been shown here to have a peak at Se 102 by analytical ultracentrifugation. The lymph VLDL fraction, therefore, does not represent chylomicrons incompletely removed during ultracentrifugation, but rather a class of triglyceride-rich particles with a flotation range distinct from that of the chylomicrons. The VLDL have also been shown in these studies to differ from chylomicrons in electrophoretic mobility and per cent lipid composition.

These differences, however, do not by themselves establish that VLDL and chylomicrons are formed as a distinct lipoprotein species, or by distinct mechanisms in the intestinal mucosal cell. In fact, our previous studies have shown that the apoprotein composition of the two fractions is similar (12). Furthermore, in the present studies gas-liquid chromatographic analysis of their triglyceride fatty acids suggests that VLDL and chylomicron triglyceride are probably derived from a common precursor pool. It is therefore possible that VLDL and chylomicrons represent separate classes of one broad spectrum of triglyceride-rich lipoproteins. The considerable range of particle size (and density) evident in both the chylomicrons and the VLDL would be consistent with this concept.

Certain differences in composition could also be accounted for by this interpretation. Zilversmit (23) has shown that in the chylomicron all of the protein and phospholipid and much of the cholesterol are present in the polar surface coat, whereas triglyceride forms the nonpolar center. Smaller particles (such as VLDL) with a larger surface-to-volume ratio, would therefore be expected to contain relatively more protein, phospholipid, and cholesterol, and less triglyceride. Fraser, Cliff, and Courtice have also obtained evidence suggesting that differences in triglyceride-to-phospholipid ratios of thoracic duct lymph chylomicrons and VLDL can be explained by differences in particle size (33). The relative decrease in triglyceride content would in turn result in an increased particle density, while the relative increase in polar surface components could at least in part account for än increased electrophoretic mobility. Thus, several of the features which distinguish VLDL from chylomicrons could be explained solely on the basis of differences in particle size between the two lipoprotein classes.

One observation, however, does not appear to be consistent with this interpretation. The studies of Zilversmit showed that the chylomicron surface coat contains free cholesterol only, whereas cholesterol esters are carried in the nonpolar triglyceride-containing center. If the VLDL simply represent small chylomicrons, then one would expect the concomitant increase in surface-tovolume ratio to be reflected by a greater free cholesterol/ ester cholesterol ratio in VLDL. However, a lower ratio was consistently observed. There is no obvious explanation to account for this discrepancy, and it is therefore possible that at least a portion of the VLDL fraction may be produced in the intestine by a process, or in a location, different from that involved in chylomicron formation.

Regardless of possible similarities or differences in their formation, intestinal lymph VLDL represent a lipoprotein fraction differing in several important respects from chylomicrons as usually defined and studied. Moreover, in flotation characteristics and in per cent lipid composition, the lymph VLDL are similar to serum VLDL, differing chiefly in their content of stearic and arachidonic acids. Although the relative abundance of these fatty acids in intestinal lymph triglycerides undoubtedly reflects the importance of biliary phospholipids as precursors, the use of whole serum and lymph triglycerides limits the quantitative interpretations which can be made. At face value, however, the data suggest that a maximum of $40 \%$ of serum triglyceride could be derived from intestinal lymph.

Although native intestinal lymph VLDL migrate with an $\alpha_{2}$ mobility in agarose, upon being mixed with VLDLfree serum they assume the $\alpha_{1}$ mobility of rat serum VLDL. This increased mobility is most likely a reflection of the adsorption of proteins already present in the serum. Such a process of adsorption of proteins onto intestinal, triglyceride-rich lipoproteins as they enter the plasma has been postulated as the mechanism by which so-called "secondary particles" are formed from "primary particles" (chylomicrons) during and after a fatty meal (34). (It should be emphasized, however, that the lymph VLDL described in the present studies are not the same as secondary particles, since the latter, like chylomicrons, are characterized by a flotation range of $S_{t}>400$.) Thus, although the per cent protein composition of native intestinal lymph VLDL is less than that reported for plasma VLDL (31), it seems likely that upon the entry of lymph VLDL into plasma this difference is reduced or eliminated. It is also possible 
that differences in the immunoelectrophoretic pattern between intestinal and serum VLDL would disappear subsequent to the mixture of intestinal VLDL with VLDL-free serum.

It is apparent from these observations that the usual methods (ultracentrifugation and electrophoresis) for isolating plasma VLDL also include VLDL of intestinal origin. Furthermore, recent electron microscopic studies have shown that intestinal VLDL are similar in size to and are otherwise indistinguishable morphologically from plasma VLDL. In addition, fasting lymph contains very few particles larger than rat plasma VLDL (300-1000 A). ${ }^{8}$ These experiments thus support the suggestion that VLDL of intestinal origin, indistinguishable from VLDL of hepatic origin, circulate in plasma in the fasting state.

Since the completion of these studies, Windmueller and Levy (32) have presented additional evidence for the intestinal production of VLDL, although their "VLDL" included all triglyceride-rich lymph lipoproteins (i.e. including chylomicrons). These investigators found total lymph triglyceride output to be about 2.7 $\mathrm{mg} / \mathrm{hr}$. On the basis of this and earlier observations (35), and published evidence that total plasma triglyceride turnover was about $30 \mathrm{mg} / \mathrm{hr}(36,37)$, the authors concluded that intestinal lymph accounted for approximately $10 \%$ of the plasma triglyceride in rats on a fatfree diet. However, it is noteworthy that in the present studies and in experiments reported by Baxter (38), the hourly lymph triglyceride output was found to be about $6 \mathrm{mg} / \mathrm{hr}$, i.e. more than twice the value reported by Windmueller and Levy. Furthermore, studies of Baker and Schotz (39) suggest that plasma triglyceride turnover in rats may be significantly lower than earlier estimates, and probably of the order of $15 \mathrm{mg} / \mathrm{hr}$. Thus, according to these values, intestinal lymph could account for up to $40 \%$ of the total plasma triglyceride turnover in fasted rats.

Earlier, Byers and Friedman (40) showed that administration of Triton WR-1339 resulted in a fourfold rise in the plasma triglyceride levels of hepatectomized rats. This rise did not occur in animals subjected to hepatectomy plus evisceration, and therefore was attributed to intestinal triglyceride production. It is of interest that although the Triton-induced increase in plasma triglyceride level observed in hepatectomized rats was only $20 \%$ of that which occurred in intact rats, it nevertheless reflected intestinal production of triglyceride under conditions in which this process was severely impaired, i.e., in which both the major source of fatty acids for the fasting intestine (bile phospholipid) (41, and present data), and the means by which

\footnotetext{
- Ockner, R. K., and A. Jones. In preparation.
}

these ultimately gain entry into the mucosal cell (bile salts), were removed. Thus, as with the findings reported here, the data of Byers and Friedman can be interpreted as suggesting that, under ordinary conditions, a larger percentage of plasma triglyceride is of intestinal origin than has been calculated by Windmueller and Levy. Experiments designed to quantitate this intestinal contribution more precisely are currently in progress.

The present studies demonstrate the considerable importance of VLDL of intestinal origin in the transport of endogenous lipids in intestinal lymph in the fasting state and suggest that they contribute to levels of plasma VLDL, from which they appear to be indistinguishable. In other studies, we have examined the role of intestinal VLDL in lymph lipid transport during the absorption of dietary fats, and have presented evidence indicating that the VLDL and chylomicron fractions differ in their response to the absorption of various long chain fatty acids. $^{*}$

\section{ACKNOWLEDGMENTS}

Analytical ultracentrifugal analysis and interpretations were accomplished with the advice and assistance of Dr. Michael Young, Biophysics Laboratory, Massachusetts General Hospital. Dr. Kurt J. Bloch, Arthritis Group, Massachusetts General Hospital, assisted in the interpretation of the immunoelectrophoresis. The manuscript was constructively reviewed by Dr. Richard Havel, University of California, San Francisco Medical Center.

This project was supported in part by grants from the John A. Hartford Foundation, Inc., and the National Institutes of Health (AM 01392 and 03014), and was conducted during Dr. Ockner's tenure of NIH Special Research Fellowship AM 36586.

\section{REFERENCES}

1. Zilversmit, D. B. 1967. Formation and transport of chylomicrons. Fed. Proc. 26: 1599.

2. Nestel, P. J., R. J. Havel, and A. Bezman. 1962. Sites of initial removal of chylomicron triglyceride fatty acids from blood. J. Clin. Invest. 41: 1915.

3. Nestel, P. J., R. J. Havel, and A. Bezman. 1963. Metabolism of constituent lipids of dog chylomicrons. $J$. Clin. Invest. 42: 1313.

4. Olivecrona, T., and P. Belfrage. 1965. Mechanisms for removal of chyle triglyceride from the circulating blood as studied with $\left[{ }^{14} \mathrm{C}\right]$ glycerol and $\left[{ }^{3} \mathrm{H}\right]$ palmitic acidlabeled chyle. Biochem. Biophys. Acta. 98: 81.

5. Dietschy, J. M., and M. D. Siperstein. 1965. Cholesterol synthesis by the gastrointestinal tract: localization and mechanisms of control. J. Clin. Invest. 44: 1311.

6. Ockner, R. K., and L. Laster. 1966. Biosynthesis of $\Delta 7$-cholesten-3 $\beta$-ol, $\Delta 5,7$-cholestadien- $3 \beta$-ol, and $\Delta 5$ cholesten- $3 \beta$-ol by guinea pig intestinal mucosa in vitro. J. Lipid Res. 7: 750.

7. Lindsey, C. A., Jr., and J. D. Wilson. 1965. Evidence for a contribution by the intestinal wall to the serum cholesterol of the rat. J. Lipid Res. 6: 173.

8. Wilson, J. D. 1968. Biosynthetic origin of serum cholesterol in the squirrel monkey: evidence for a contribution by the intestinal wall. J. Clin. Invest. 47: 175 . 
9. Havel, R. J., and A. Goldfien. 1961. The role of the liver and of extrahepatic tissues in the transport and metabolism of fatty acids and triglycerides in the dog. J. Lipid Res. 2: 389.

10. Roheim, P. S., L. I. Gidez, and H. A. Eder. 1966. Extrahepatic synthesis of lipoproteins of plasma and chyle: role of the intestine. J. Clin. Invest. 45: 297.

11. Ockner, R. K., and K. J. Isselbacher. 1968. Intestinal lymph very-low-density lipoprotein: role in cholesterol metabolism. J. Clin. Invest. 47: 73a.

12. Ockner, R. K., K. J. Bloch, and K. J. Isselbacher. 1968. Very-low-density lipoprotein in intestinal lymph: evidence for presence of the A protein. Science (Washington). 162: 1285 .

13. Bollman, J. L., J. C. Cain, and J. H. Grindlay. 1948. Techniques for the colelction of lymph from the liver, small intestine, or thoracic duct of the rat. J. Lab. Clin. Med. 33: 1349.

14. Bollman, J. L. 1948. A cage which limits the activity of rats. J. Lab. Clin. Med. 33: 1348.

15. Dole, V., and J. T. Hamlin III. 1962. Particulate fat in lymph and blood. Physiol. Rev. 42: 674.

16. Havel, R. J., H. A. Eder, and J. H. Bragdon. 1955. The distribution and chemical composition of ultracentrifugally separated lipoproteins in human serum. J. Clin. Invest. 34: 1345.

17. DeLalla, O. F., and J. W. Gofman. 1954. Ultracentrifugal analysis of serum lipoproteins. Methods Biochem. Anal. 1: 459.

18. Van Handel, E., and D. B. Zilversmit. 1957. Micromethod for the direct determination of serum triglycerides. J. Lab. Clin. Med. 50: 152.

19. Zlatkis, A., B. Zak, and A. J. Boyle. 1953. A new method for the direct determination of serum cholesterol. J. Lab. Clin. Med. 41: 486.

20. Thompson, G. R., R. K. Ockner, and K. J. Isselbacher. 1969. Effect of mixed micellar lipid on the absorption of cholesterol and vitamin $\mathrm{D}_{3}$ into lymph. J. Clin. Invest. 48: 87.

21. Marinetti, G. V. 1962. Chromatographic separation, identification and analysis of phosphatides. J. Lipid Res. 3: 1 .

22. Lowry, O. H., N. J. Rosebrough, A. L. Farr, and R. J. Randall. 1951. Protein measurement with the Folin phenol reagent. J. Biol. Chem. 193: 265.

23. Zilversmit, D. B. 1965. The composition and structure of lymph chylomicrons in dog, rat, and man. J. Clin. Invest. 44: 1610 .

24. Folch, J., M. Lees, and G. H. Sloane-Stanley. 1957. A simple method for the isolation and purification of total lipids from animal tissues. J. Biol. Chem. 226: 497.
25. Lipsky, S. R., and R. A. Landowne. 1963. Identification of fatty acids by gas chromatography. In Methods in Enzymology, Vol. VI. S. P. Colowick and N. O. Kaplan, editors. Academic Press Inc., New York. 513-537.

26. Lees, R. S., and F. Hatch. 1963. Sharper separation of lipoprotein species by paper electrophoresis in albumincontaining buffer. J. Lab. Clin. Med. 61: 518.

27. Laurell, C. B. 1965. Electrophoretic microheterogeneity of serum $\alpha_{1}$-antitrypsin. Scand. J. Clin. Lab. Invest. 17: 271.

28. Wieme, R. J. 1959. Improved technique of agar-gel electrophoresis on microscope slides. Clin. Chim. Acta. 4: 317.

29. Snedecor, G. W., and W. G. Cochran. 1967. Statistical Methods. Iowa State University Press, Ames. 6th edition.

30. Scanu, A. M. 1965. Factors affecting lipoprotein metabolism. Advan. Lipid Res. 3: 64.

31. Camejo, G. 1967. Structural studies of rat plasma lipoproteins. Biochemistry. 6: 3228.

32. Windmueller, H. G., and R. I. Levy. 1968. Production of $\beta$-lipoprotein by intestine in the rat. J. Biol. Chem. 243: 4878.

33. Fraser, R., W. J. Cliff, and F. C. Courtice. 1968. The effect of dietary fat load on the size and composition of chylomicrons in thoracic duct lymph. Quart J. Exp. Physiol. Cog. Med. Sci. 53: 390.

34. Bierman, E. L., and D. E. Strandness, Jr. 1966. Formation of secondary fat particles from lymph chylomicrons in the dog. Amer. J. Physiol. 210: 13.

35. Windmueller, H. G., and R. I. Levy. 1967. Total inhibition of hepatic $\beta$-lipoprotein production in the rat by orotic acid. J. Biol. Chem. 242: 2246.

36. Windmueller, H. G. 1964. Orotic acid-induced, adeninereversed inhibition of hepatic lipoprotein secretion in the rat. J. Biol. Chem. 239: 530.

37. Otway, S., and D. S. Robinson. 1967. The use of a nonionic detergent (Triton WR 1339) to determine rates of triglyceride entry into the circulation of the rat under different physiological conditions. J. Physiol. 190: 321 .

38. Baxter, J. H. 1966. Origin and characteristics of endogenous lipid in thoracic duct lymph in rat. J. Lipid Res. 7: 158 .

39. Baker, N., and M. Schotz. 1967. Quantitative aspects of free fatty acid metabolism in the fasted rat. J. Lipid Res. 8: 646

40. Byers, S. O., and M. Friedman. 1960. Site of origin of plasma triglyceride. Amer. J. Physiol. 210: 13.

41. Shrivastava, B. K., T. G. Redgrave, and W. J. Simmonds. 1967. The source of endogenous lipid in the thoracic duct lymph of fasting rats. Quart J. Exp. Physiol. Cog. Med. Sci. 52: 305. 